\title{
Study on Energy-Saving Transformation Technologies for Green Buildings
}

\author{
Yupeng Yang \\ Master of Science in Management, lecturer,Architecture Engineering Department ,at Logistics \\ University of Chinese People's Armed Police Force,Tianjin,300309,China
}

hunter2011@foxmail.com

Keywords: Energy Saving, Building Transformation, Green Building.

\begin{abstract}
Buildings were large energy consumption in the whole society. At present, building energy consumption of our country accounted for $20.7 \%$ in consumption terminals of the whole society, and $95 \%$ existing buildings were high energy consumption buildings. Therefore, the existing buildings energy saving reconstruction became top priority of the building energy saving engineering. At present, in order to avoid wasting energy and improve the working and living environment, it became our current urgent and important problems which must be quickly resolved to carry out the existing buildings energy saving reconstruction.
\end{abstract}

\section{Introduction}

As social economy developing, energy shortage become urgent day by day .The architectural trade takes about $30 \%$ in our country' s total energy consumption. So the energy efficiency in buildings has become an important issue for sustainable development in China. The key to achieve the energy efficiency target is the residential buildings because it occupies more than $60 \%$ of total building floor area. At present, most of our country' s extant residence buildings become high energy consumption buildings and many new buildings become high energy consumption buildings when they are built up. So whether we can turn transformation into reality decides whether we can achieve the energy efficiency target. Now the transformation is carrying on largely. But because of the shortage of technology, money and other factors, the project goes slowly.

\section{Energy-Saving Transformation Technologies for Green Buildings}

From the perspective of energy saving building, heat insulation and shading of facades, roofs and windows is the focus of building energy-saving transformation. Energy-saving transformation is basis of original building structure, to enhance its heat preservation and heat insulation performance. in the transformation process, we should not destroy the structure of the original building, and minimize the load bearing of the outer wall and the roof.

Facades Transformation. A large part of building energy consumption is from facades. Driven by indoor and outdoor temperature difference, a steady stream of heat gain or cooling consumption is delivered through the wall into the room. Thus, if the insulation performance of facades is poor, the external environment will directly impact the indoor environment, which can cause human body's discomfort. According to thermal design specification, under the natural ventilation conditions, the maximum temperature of east and west facades and the inner surface of the roof should meet the inequality as follow:

$$
\theta_{i \cdot \max } \leq t_{e \cdot \max }
$$

In the inequality, $\theta_{i \cdot \max }$ refers to temperature of the inner surface structure; $t_{e \cdot \max }$ refers to maximum temperature of external environment.

(1)Facades insulation techniques. On the existing exterior wall of the buildings, fix the heat insulation material in it with bonding agents, and cover the protective layer or finish material. Common insulation materials include extruded polystyrene board, polystyrene foam board, mineral wool board, glass cotton blanket, powder polystyrene particles insulation mortar, etc. Its principle is 
based on the low thermal conductivity and good thermal insulation of the insulation materials, so the thermal resistance of facades would be significantly increased after adding this layer of insulation material, so as to achieve the purpose of reducing the energy consumption of buildings.

When there is large temperature fluctuation indoors, since there is "warm underwear" in the outer wall, it can ensure a good thermal stability chamber, and meanwhile it can also play a protective role for the main structure of building facades. In addition, the construction process is not complicated, and has little effect on daily life of interior personnel in the building.

As many insulation materials are flammable, Special attention should be paid to the fire prevention in the construction process. However, if construction workers do not meet the technical requirements, external walls cracking or collapsing is likely to occur, and it will seriously affect the existing building energy saving effect and aesthetics. The construction technique of facades insulation is shown in Fig. 1:

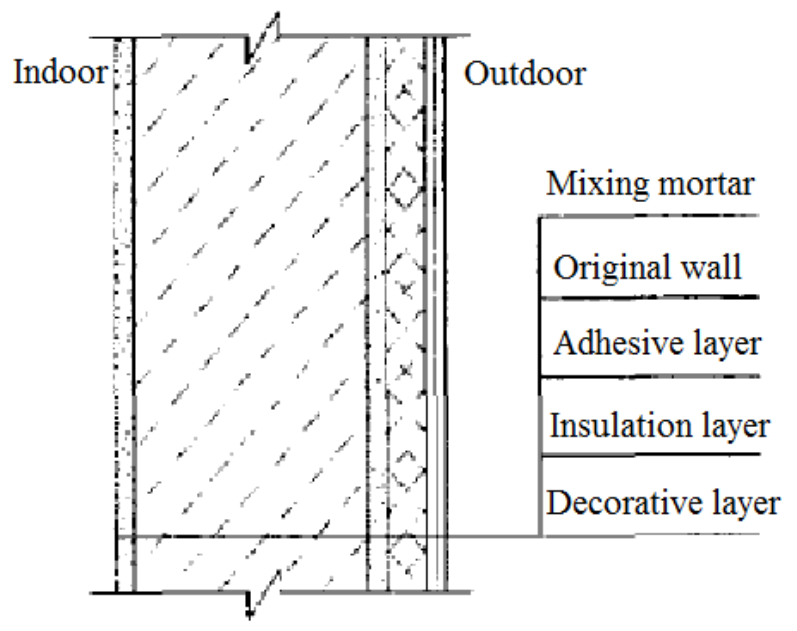

Fig. 1. Construction technique of facades insulation

(2) Heat-reflective coating techniques. Heat-reflective coating is a coating which can reflects solar radiation, which is mainly composed of packing materials of high-performance resin, high solar reflectance and high infrared emissivity. When solar radiation irradiates into the building envelope, this coating can timely transfer heat into the external environment through reflection and emission effects. Heat-reflective coating being painted on existing building's exterior surface, it can reduce the intensity of solar radiation on facades, and reduces the heat absorption from solar radiation by facades, thus obtain a good exterior insulation effect. The basic structure of heat-reflective coating for green building is shown as Fig. 2:

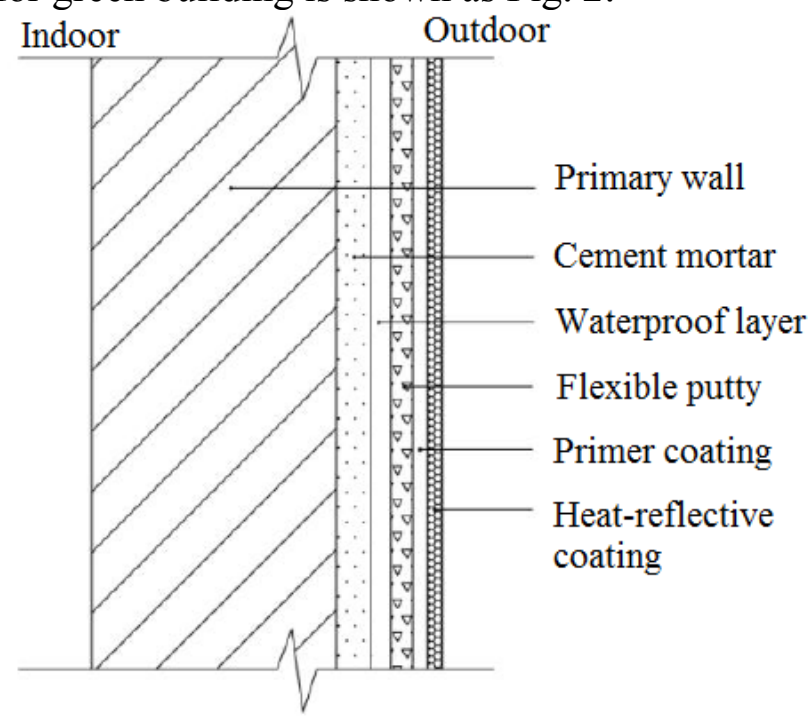

Fig. 2. Basic structure of heat-reflective coating for green building 
(3) Facades greening techniques. Planting trees and flowers can not only beautify the external environment, but also form a very good shading effect, so we adopt facades greening techniques for building energy saving transformation. On the one hand, making use of the occlusion effect of plant leaves, the plants would reduce solar heat gain of building envelope structure; on the other hand, photosynthesis and transpiration of green vegetation would help to improve the thermal environment of the surrounding buildings.

The most common techniques of facades greening is to introduce some lianas such as Ivy and Naga Haruto, and allow them attached to the whole facades. Such greening technique is common in some old buildings. With this greening technique, the building will look more ecological and full of historical heritage.

Roof Transformation. Compared to facades, the surface area that roof accounts is smaller. However, the roof is located on the top of the building, and accepts direct solar radiation, so its impact on building energy consumption is quite substantial.

(1) Roof insulation techniques. Similar to facades insulation, the energy saving transformation of building roof can also make use of heat insulating material to increase the thermal resistance and thermal inertia of the roof. For building energy saving transformation in subtropical region, the peak temperature of inner surface is better retard until before dawn. At this time, the outdoor temperature has dropped, but the peak temperature would bring more stable internal environment. In addition, the top floor room can also get certain insulation effect in winter.

(2) Porous material roofing techniques. Lay porous material on building roof, such as aerated concrete. Porosity of aerated concrete can be up to $70 \% \sim 80 \%$, while moisture content up to $60 \%$ $70 \%$. It is able to absorb water when raining; in sunny day, under the influence of solar radiation and natural ventilation, the storage water would evaporate and take lot of heat. In summer, we carry out a series of measurement experiments on the water-storage roof. The results show that, the inner surface temperature of the roof can be decreased by $3 \sim 5$. When faced with continuous high temperature weather and without rain, the moisture inside the aerated concrete is completely evaporated, but because due to the presence of large amount of air voids in dried aerated concrete, its thermal conductivity is still quite small. Therefore, aerated concrete roofing technique is widely used in subtropical regions.

(3) Roof greening techniques. Roof greening technique is also one of the most widely used transformation techniques. Plant leaves surrounded by each other can block and reflect solar radiation, and thus reduce the outdoor temperature on roof. However, although technical advantages of roof greening techniques highlights, in actual application, it needs to do a good job of existing buildings roofing waterproofing, drainage and other measures. Roof greening effect is shown as Fig. 3:

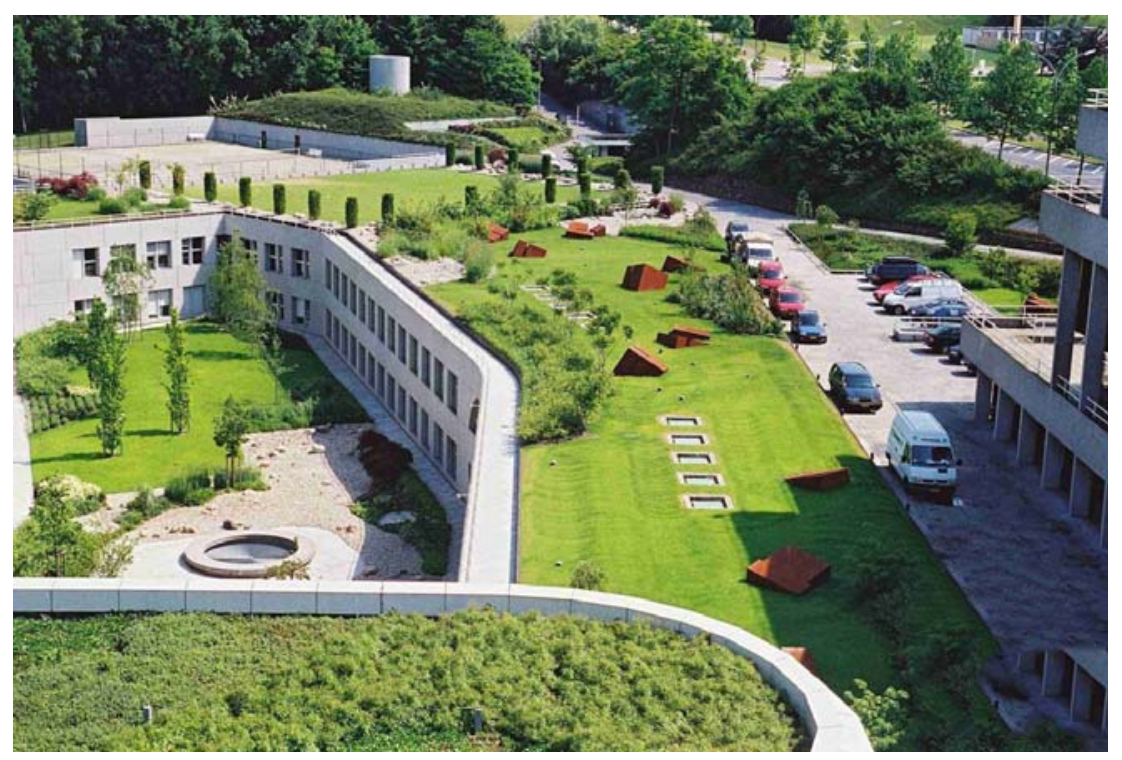

Fig. 3. Roof greening effect 


\section{References}

[1] Chun-Lan L V. Application of enclosure structure thermal insulation in residential building energy-saving transformation. Shanxi Architecture, 2013.

[2] S. Zhang, Y.L. Wan, W.D. Wang, et al. Analysis of Energy Saving and Heat Metering Comprehensive Transformation of Old Buildings. Value Engineering, 2013.

[3] Zhi-Bin L I, Qian X. Analysis of Energy-saving Transformation Measures and Effect of Large-scale Public Buildings. Construction Energy Conservation, 2009.

[4] Q. Zhao. Exploration on building wall energy-saving transformation construction. Shanxi Architecture, 2011.

[5] G. Tang. Economic analysis of the envelope energy-saving transformation for a local public building in Shanghai. Wall Materials Innovation \& Energy Saving in Buildings, 2009.

[6] X.D. Peng, Y. Xun, X.H. Wei, et al. Energy-saving transformation of existing building in hot-summer and cold-winter area. Shanxi Architecture, 2013.

[7] H.H. Yuan. The analysis on the energy saving Transformation of Shenzhen university Yuanping stadium. Supervision Test \& Cost of Construction, 2011. 